\section{References}

1. Mangano DT, Miao Y, Vuylsteke A, Tudor IC, Juneja R, Filipescu D, et al. Mortality associated with aprotinin during 5 years following coronary artery bypass graft surgery. JAMA. 2007;297:471-9.

2. Brown JR, Birkmeyer NJ, O'Connor GT. Meta-analysis comparing the effectiveness and adverse outcomes of antifibrinolytic agents in cardiac surgery. Circulation. 2007;115:2801-13.

3. Coleman CI, Rigali VT, Hammond J, Kluger J, Jeleniowski KW, White CM. Evaluating the safety implications of aprotinin use: The Retrospective Evaluation of Aprotinin in Cardio Thoracic Surgery (REACTS). $J$ Thorac Cardiovasc Surg. 2007; 133:1547-52.
4. US Food and Drug Administration. Early communication about an ongoing safety review: aprotinin injection (marketed as Trasylol). Center for Drug Evaluation and Research website 2007 Oct 25 [cited 2007 Dec 6]. Available from: http://www.fda. gov/cder/drug/early_comm/aprotinin.htm

5. Skillington PD, Fuller JA, Grigg LE, Yapanis AG, Porter GF. Ross procedure. Inserting the autograft using a fully supported root replacement method; techniques and results. J Heart Valve Dis. 1999;8:593-600.

6. Punjabi PP, Wyse RKH, Taylor KM. Role of aprotinin in the management of patients during and after cardiac surgery. Exp Opin Pharmacother. 2000;1: $1353-65$.

\title{
Left main compression syndrome by idiopathic pulmonary artery aneurysm caused by medial necrosis Erdheim-Gsell combined with bicuspid pulmonary valve
}

\author{
Daniel Jodocy, MD, ${ }^{\mathrm{a}}$ Guy J. Friedrich, MD,${ }^{\mathrm{a}}$ Johannes O. Bonatti, MD ${ }^{\mathrm{c}}$ Silvana Müller, MD, ${ }^{\mathrm{b}}$ \\ Guenther Laufer, MD, ${ }^{\mathrm{c}}$ Otmar Pachinger, MD, FECTS, ${ }^{\mathrm{a}}$ Patrizia Moser, MD,${ }^{\mathrm{d}}$ and \\ Gudrun M. Feuchtner, MD, ${ }^{\mathrm{b}}$ Innsbruck, Austria
}

A 71-year-old man with episodes of dyspnea presented with stress-induced anterior myocardial ischemia on myocardial single photon emission computed tomography. $\mathrm{He}$ was referred for invasive angiography, which revealed a left main coronary artery ostial catheter pressure decrease and an atypical configuration of the left main stem (Figure 1, A).

\section{CLINICAL SUMMARY}

Cardiac electrocardiogram-gated 64-slice computed tomography was performed, showing a giant pulmonary aneurysm ( $6 \mathrm{~cm}$ in diameter) (Figure 1, B-D) that significantly $(>50 \%)$ compressed the left main coronary artery during both systole and diastole. A tender bicuspid pulmonary valve without degenerative lesion (Figure 1, $D$, inlay bottom left) was found.

Pulmonary valve stenosis, pulmonary artery hypertension, and any congenital heart disease, such as atrial or ventricular septal defects, were excluded by transesophageal echocardiography. The patient underwent cardiac surgery

From the Departments of Cardiology, ${ }^{\mathrm{a}}$ Radiology, ${ }^{\mathrm{b}}$ Cardiac Surgery, ${ }^{\mathrm{c}}$ and Pathology, Innsbruck Medical University, Innsbruck, Austria.

Received for publication Jan 21, 2008; accepted for publication Feb 7, 2008.

Address for reprints: Gudrun M. Feuchtner, MD, Innsbruck Medical University, Department of Radiology II, Anichstr. 35, A-6020 Innsbruck, Austria, Europe

(E-mail: Gudrun.Feuchtner@i-med.ac.at).

J Thorac Cardiovasc Surg 2009;138:234-6

$0022-5223 / \$ 36.00$

Copyright (C) 2009 by The American Association for Thoracic Surgery

doi:10.1016/j.jtcvs.2008.02.076 under median sternotomy and cardiopulmonary bypass, including double left internal thoracic artery/left anterior descending and aortocoronary saphenous vein grafting to the circumflex artery and surgical reconstruction of the pulmonary artery aneurysm. Pathohistology of the pulmonary artery demonstrated degenerative mucoid medial necrosis Erdheim-Gsell (Figure 2). The patient was discharged on the seventh postoperative day. A 3-month follow-up was uneventful.

\section{DISCUSSION}

"Left main compression syndrome", is a rare phenomenon that is defined as a functional compression of the left main coronary artery, for example, between a dilated pulmonary artery more than $4 \mathrm{~cm}$ in diameter ${ }^{2}$ and the aortic root, or an aneurysm of the sinus of Valsalva. ${ }^{3}$

Pulmonary artery aneurysms are most commonly associated with congential heart disease, such as persistent ductus Botalli, atrial or ventricular septal defects, or tetralogy of Fallot ${ }^{4}$ or develop after pulmonary valve stenosis. Idiopathic pulmonary artery aneurysms are rare, ${ }^{4,5}$ with an estimated incidence of 1 in 13,696 in an autopsy series. ${ }^{5}$ Similar to ascending aortic aneurysm, idiopathic pulmonary aneurysm may be associated with the presence of congenital bicuspid pulmonary valves, ${ }^{6}$ a rare entity ${ }^{7}$ in the absence of congenital heart disease. However, in contrast with our case, the study by Sughimoto and colleagues ${ }^{6}$ did not find medial necrosis.

In our patient, cardiac electrocardiogram-gated multislice computed tomography was the key to clarify the atypical presentation of left main stenosis on invasive coronary 

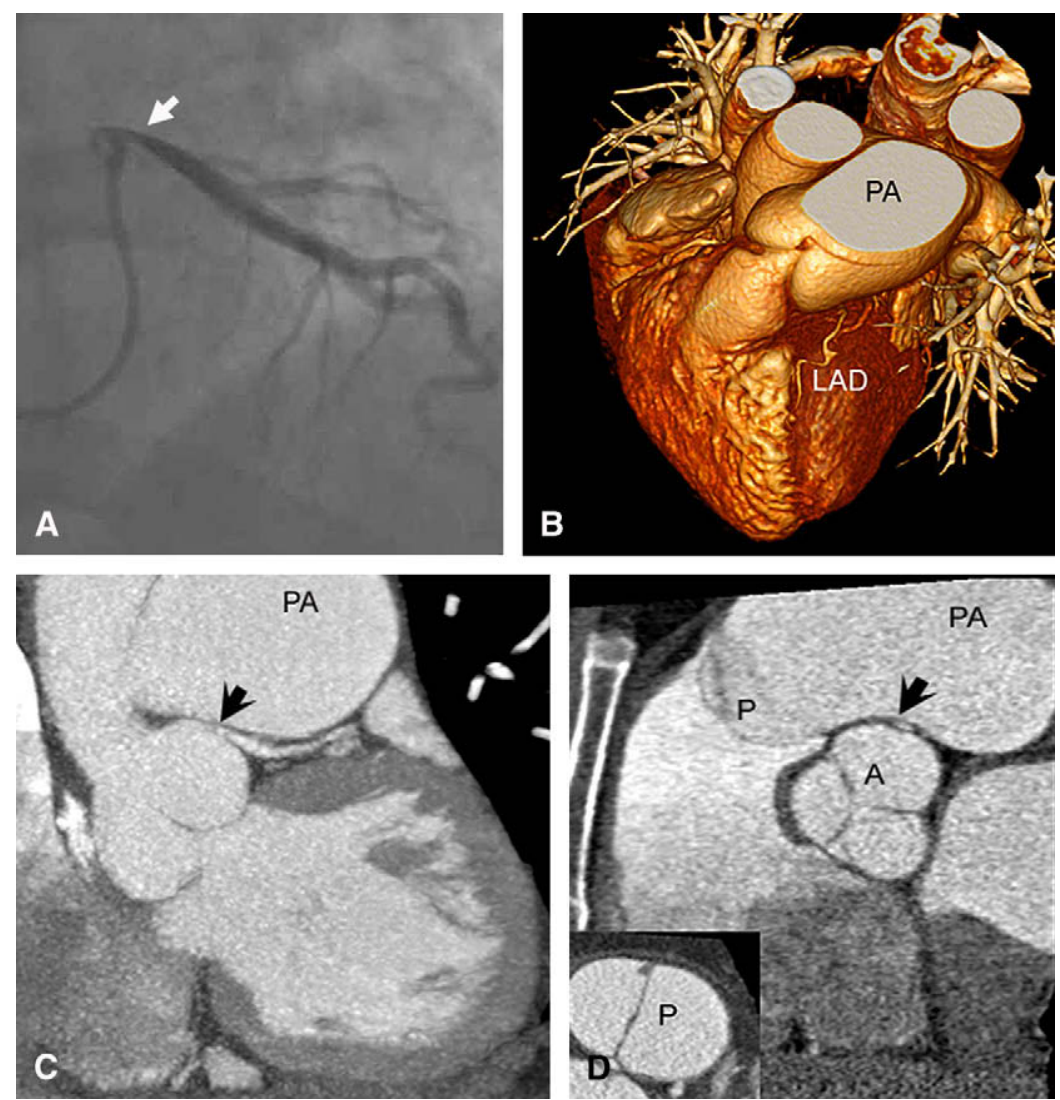

FIGURE 1. Left main compression syndrome (arrows). Compression of left main coronary artery between the giant isolated pulmonary artery and the aortic root. Invasive angiography (A), cardiac electrocardiogram-gated multislice computed tomography (B-D); 3-dimensional volume rendering technique (B) of the left anterior descending coronary artery; left coronary oblique view (C); and left sagittal oblique view (D) with inlay left bottom showing transverse plane of tender bicuspid pulmonary valve without degenerative lesions. $P A$, Pulmonary artery; $L A D$, left anterior descending; $P$, pulmonary valve; $A$, aorta.

angiography and to make the correct diagnosis of "left main compression syndrome" and its causative agent, an idiopathic pulmonary artery aneurysm.

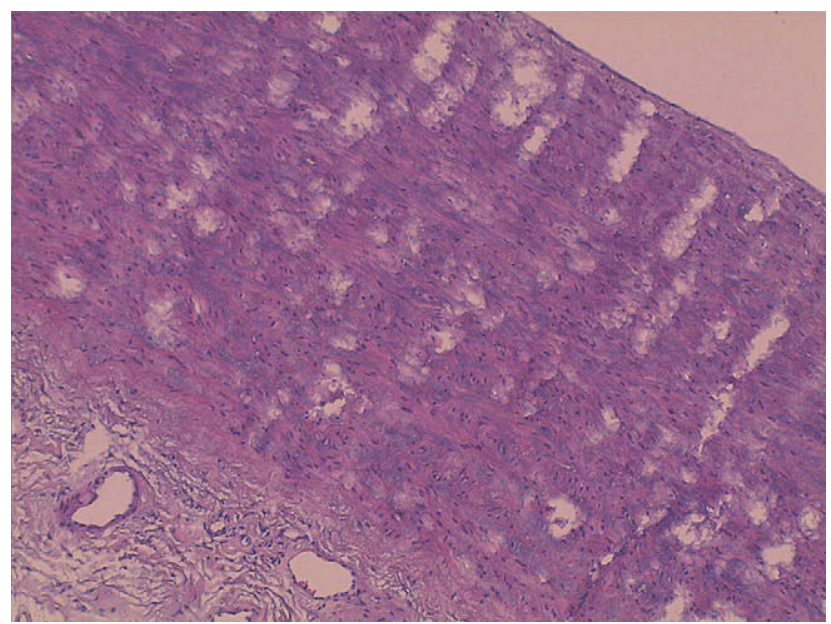

FIGURE 2. Medial necrosis Erdheim-Gsell. Pathohistology of the pulmonary artery shows mucoid degeneration and areas of necrosis in the tunica media.

\section{CONCLUSIONS}

Surgical treatment of pulmonary artery aneurysm is controversial ${ }^{8-10}$ because the risk of rupture is low given its rather low intravascular pressure, but sudden cardiac death has been reported in dissecting aneurysm. ${ }^{5}$ Attributing factors for dissection and rupture may be pulmonary hypertension and congenital ventricular septal defects with left-to-right shunting. ${ }^{5}$ In our patient, we considered surgical treatment of the pulmonary aneurysm because surgical coronary revascularization of the left main coronary artery was indicated in a simultaneous fashion.

\section{References}

1. Kajita LJ, Martinez EE, Ambrose JA, et al. Extrinsic compression of the left main coronary artery by a dilated pulmonary artery: clinical, angiographic, and hemodynamic determinants. Catheter Cardiovasc Interv. 2001;52:49-54.

2. Mesquita SM, Castro CR, Ikari NM, Oliveira SA, Lopes AA. Likelihood of left main coronary artery compression based on pulmonary trunk diameter in patients with pulmonary hypertension. Am J Med. 2004;116:369-74.

3. Ramirez-Marrero MA, Alonso Briales JH, Lopez-Rincon F. Resuscitated sudden cardiac death caused by left main coronary artery compression by an aneurysm of the sinus of Valsalva. Eur Heart J. 2007;28:2959.

4. Deterling R, Clagett $\mathrm{O}$. Aneurysm of the pulmonary artery: review of the literature and report of a case. Am Heart J. 1947;34:471-99. 
5. Graham JK, Shehata B. Sudden death due to dissecting pulmonary artery aneurysm: a case report and review of the literature. Am J Forensic Med Pathol. 2007;28:342-4.

6. Sughimoto K, Nakano K, Gomi A, Nakatani H, Nakamura Y, Sato A. Pulmonary artery aneurysm with ascending aortic aneurysm concomitant with bilateral bicuspid semilunar valves. Ann Thorac Surg. 2006;82:2270-2.

7. Orrit J, Mestres CA, Agusti E, Pomar JL. Isolated bicuspid pulmonary valve: an unusual finding. J Heart Valve Dis. 2004;13:521-2.
8. Vural AH, Türk T, Ata Y, Göncü T, Ozyazicioglu A. Idiopathic asymptomatic main pulmonary artery aneurysm: surgery or conservative management? A case report. Heart Surg Forum. 2007;10:E273-5.

9. Salhab K, McLarty A. Idiopathic pulmonary artery aneurysm. Thorac Cardiovasc Surg. 2007;55:329-31.

10. Casselman F, Meyns B, Herygers P, Verougstraete L, Van Elst F, Daenen W. Pulmonary artery aneurysm: is surgery always indicated? Acta Cardiol. 1997;52: 431-6.

\title{
Aortic pseudoaneurysm compressing the left coronary artery
}

\author{
George V. Moukarbel, MD, ${ }^{\mathrm{a}}$ Hani Jneid, MD, ${ }^{\mathrm{a}}$ Jennifer D. Walker, MD, ${ }^{\mathrm{b}}$ Joseph M. Garasic, MD, ${ }^{\mathrm{a}}$ \\ and Thomas J. Wang, MD, ${ }^{\mathrm{a}}$ Boston, Mass
}

We report a patient with an aortic pseudoaneurysm compressing the left coronary artery, causing acute ischemic left ventricular dysfunction.

\section{CLINICAL SUMMARY}

A 52-year-old man presented with acute myocardial infarction and cardiogenic shock 18 months after undergoing bioprosthetic mitral valve and homograft aortic root replacement for a dilated aortic root and severe aortic and mitral insufficiency. His cardiac catheterization at the time of surgery showed normal coronary arteries (Figure $1, A$ ). On presentation to the Massachusetts General Hospital, he was noted to have severe left ventricular dysfunction, elevated cardiac enzymes (CK-MB $50.4 \mathrm{ng} / \mathrm{mL}$; troponin T $5.03 \mathrm{ng} / \mathrm{mL}$ ), and cardiogenic shock. The patient underwent emergency placement of an intra-aortic balloon pump for hemodynamic support. Coronary angiography (Figure $1, B$ ) revealed narrowing of the distal left main artery, severe slit-like narrowing of the proximal left anterior descending artery (Figure 1, $B$, arrow) and total occlusion of the left circumflex artery (Figure 1, $B$, broken arrow), for which he underwent successful stenting (Figure 1,C) with clinical improvement. Computed tomographic angiography (Figure 1, D and $E$ ) demonstrated 2 large pseudoaneurysms arising from the ascending aorta. The first was at the level of the sinotubular junction (Figure 1, $D$ and $E$, broken arrow) impinging on the left main (Figure 1, $D$, arrow) and proximal left anterior descending artery (Figure 1, $E$, arrow), and the second was at the level of the main pulmonary artery (Figure 1,D and $E$,

From the Divisions of Cardiology ${ }^{\mathrm{a}}$ and Cardiac Surgery, ${ }^{\mathrm{b}}$ Massachusetts General Hospital, Harvard Medical School, Boston, Massachusetts.

Received for publication Feb 5, 2008; accepted for publication Feb 14, 2008.

Address for reprints: George V. Moukarbel, MD, Cardiology Division, GRB-800, Massachusetts General Hospital, Harvard Medical School, 55 Fruit Street, Boston,

MA 02114 (E-mail: moukarbel.george@mgh.harvard.edu).

J Thorac Cardiovasc Surg 2009;138:236-7

$0022-5223 / \$ 36.00$

Copyright (c) 2009 by The American Association for Thoracic Surgery doi: 10.1016/j.jtcvs.2008.02.077 asterisk). The patient later underwent successful excision of the pseudoaneurysms and redo-composite aortic root replacement.

\section{DISCUSSION}

Extrinsic compression of the left main coronary artery is a relatively uncommon condition that carries a high mortality rate, particularly when it progresses quickly. Underlying structural abnormalities include dilated pulmonary artery, ${ }^{1,2}$ periannular extension of aortic endocarditis, ${ }^{3}$ metastatic tumors, ${ }^{4}$ pseudoaneurysm of the mitral-aortic intervalvular fibrosa, ${ }^{5}$ and left ventricular aneurysms. ${ }^{6}$ Our patient had previous aortic root surgery and developed pseudoaneurysms at the surgical sites. The current coronary angiography findings and the completely normal angiogram 18 months earlier indicated an extrinsic compression as the underlying cause. Percutaneous intervention was undertaken as a bridge to final surgical excision of the pseudoaneurysms to stabilize the patient and improve his cardiac function. It is important to recognize this condition when treating acute coronary syndrome in patients with a history of aortic surgery and avoid the administration of fibrinolytic therapy. Percutaneous coronary intervention with stenting may be a reasonable therapeutic strategy to impart acute reperfusion and hemodynamic improvement before proceeding with the more definitive surgical correction. This case also illustrates the importance of computed tomographic angiography for the diagnosis and management of this condition.

\section{References}

1. Patrat JF, Jondeau G, Dubourg O, Lacombe P, Rigaud M, Bourdarias JP, et al. Left main coronary artery compression during primary pulmonary hypertension. Chest. 1997;112:842-3.

2. Bijl M, Bronzwaer JG, van Rossum AC, Verheugt FW. Angina pectoris due to left main coronary artery compression in Eisenmenger ductus arteriosus. Am Heart J. 1993; 125:1767-71.

3. Cripps T, Guvendik L. Coronary artery compression caused by abscess formation in infective endocarditis. Int J Cardiol. 1987;14:99-102. 